DIW BERLIN

Discussion

Papers

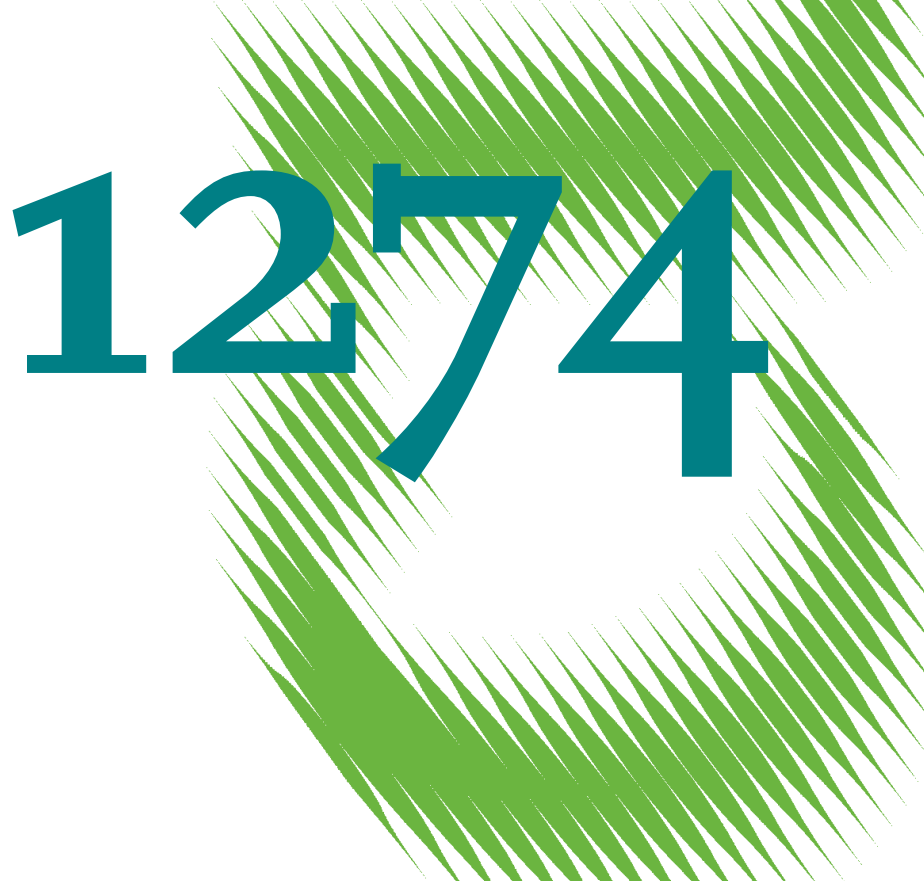

A Market Screening Model for Price Inconstancies

Empirical Evidence from German Electricity Markets 
Opinions expressed in this paper are those of the author(s) and do not necessarily reflect views of the institute.

IMPRESSUM

(C) DIW Berlin, 2013

DIW Berlin

German Institute for Economic Research

Mohrenstr. 58

10117 Berlin

Tel. $+49(30) 89789-0$

Fax +49 (30) $89789-200$

http://www.diw.de

ISSN print edition $1433-0210$

ISSN electronic edition 1619-4535

Papers can be downloaded free of charge from the DIW Berlin website:

http://www.diw.de/discussionpapers

Discussion Papers of DIW Berlin are indexed in RePEc and SSRN:

http://ideas.repec.org/s/diw/diwwpp.html

http://www.ssrn.com/link/DIW-Berlin-German-Inst-Econ-Res.html 


\title{
A Market Screening Model for Price Inconstancies: Empirical Evidence from German Electricity Markets
}

\author{
Korbinian von Blanckenburg*, Marc Hanfeld**, Konstantin A. Kholodilin***
}

\begin{abstract}
In this paper, we develop a market screening model to detect inconstancies in price changes. Although there is a long history of industrial organization research of collusion, price setting behavior, and conduct - a robust model to detect structural changes in market structure was missing so far. Our non-parametric approach closes this gap and can be used as a tentative warning system for emerging collusions. Based on the theoretical and empirical results from previous research, we describe requirements of screenings, develop a model, and illustrate our approach with a short market simulation. Finally, we apply the model to the German electricity market. According to our results, between 2001 and 2011 energy suppliers appear to be successful in controlling the market price for several phases.
\end{abstract}

Keywords: Market screening, collusion, competition policy, energy markets

JEL: L10, L60

* University of Kassel, Germany

Corresponding e-mail: korbinian@vonblanckenburg.de

** Hochschule Zittau/Görlitz (University of Applied Sciences)

*** Deutsches Institut für Wirtschaftsforschung (DIW Berlin), Macroeconomic Department 


\section{Introduction}

The development of a proper screening model for competition policy has gained in importance over the last years, especially with respect to price collusion. Although the European Commission has not dealt with many cases, between 2004 and 2011 competition authorities in Europe carried out over one hundred market-monitoring actions, about 1,300 merger cases, and 180 antitrust cases - half of which were cartels. ${ }^{1}$

The aim of this paper is to develop an empirical model that consistently measures shifts in price variation, which can be used by antitrust authorities for screening purposes. The approach can also be useful as an additional technique for establishing damages in antitrust legal proceedings concerning price fixing agreements.

Previous findings have shown that collusive behavior can be detected by analyzing empirical data. In this context, Sherwin and Stigler (1985), Bolotova et al. (2008), Böckers et al. (2011), Blanckenburg and Geist (2009, 2011) analyze price dispersion. Blanckenburg et al. (2012) compare the distribution of price changes between collusive and non-collusive periods for eleven major cartels. They found that 9 out of 11 cartels were successful in controlling the market price for a number of years. However, the presented cases were already prosecuted by the European antitrust authority.

In this paper, we present a model to detect an unknown suspicion of a collusive period. A general requirement is to adapt an appropriate method that screens time series data independently. The model is illustrated by applying it for German energy markets due to the fact that on these markets, collusion periods can be supposed in the past. In order to simplify the understanding of the developed methodology, we provide a short example and a market simulation. In this exemplary analysis, we assume a typical power market, where supplier

\footnotetext{
1 Mentioned by J. Almunia (EU Commission) at "Antitrust enforcement: Challenges old and new 19th International Competition Law Forum", St. Gallen (8 June 2012).
} 
may be able to manipulate prices. We simulate time series for different manipulation scenarios and show how our empirical approach works.

\section{Requirement of screening models}

A typical framework for analysing market power in industrial organization is to estimate structural models in order to gain an impression about the degree of competition in certain markets. Heijnen et al. (2012) develop, for example, a method to identify statistical evidence of clustering of outlets that score high on some characteristic that is consistent with collusive behavior. Harrington $(2005,2008)$ mentions requirements for systematic and ubiquitous market screenings. Evidence of collusive patterns must be discernible by just looking at the available data, such as prices. The procedure should be automatable so that it can be carried out with minimal human input. However, for many markets exact and reliable data are notoriously difficult to obtain.

Market manipulations lead to multiple changes in industry structure and behavior. Stigler (1964) states that price dispersion is ubiquitous, even for homogenous products. It takes place when different suppliers offer different prices for the same good on a certain market. Several studies, including Carlson and McAfee (1983), Carlton (1986) demonstrate that price dispersion is greater when industry concentration declines. Furthermore, according to Connor (2005), cartels usually fix prices either by announcing list prices to buyers and agreeing to sell only at this price or by agreeing to sell at some lower "floor" (minimum) price or at a "target" (average) price below list. Some cartels also agree to eliminate or restrict discounts, which reduces the variance of prices. There is some empirical support for this hypothesis. Abrantes-Metz et al. (2006) examine the effects of a bid-rigging cartel in frozen perch sold to the U.S. Department of Defence. As a result, they find a relatively small difference in price, but a huge difference in variance, when comparing the collusive and 
competitive regimes. The average price dropped $23 \%$ after the conspiracy was detected, but even more significant, the variance of price increased by $145 \%$, compared to the variance during the cartel period. For the lysine cartel, Bolotova et al. (2008) find support for the hypotheses that the mean increases and the variance decreases in the cartel period relative to the competitive regimes. Citric acid prices examined in that study confirm the mean price hypothesis, but fail to support the variance hypothesis. The variance was even higher as compared to the pre-cartel and post-cartel periods. Blanckenburg and Geist (2009) find a significantly lower variance in price changes for the cartel period of the German cement industry 1981-2001, compared to the pre- and post-cartel periods. Hüschelrath and Veith (2011) argue that customers of hard core cartels can have both incentives and possibilities to detect such agreements on their own initiative through the use of market-specific data sets. However, a robust screening needs adequate data and methods.

\section{An empirical approach to detect inconsistencies}

This section describes an empirical approach to detection of the cartel periods. The idea is that by analyzing the distribution of the growth rates of price for a product in two different time intervals we can judge whether the price setting for this product in each of the sub-periods has a different nature and which of the sub-periods can be characterized as a free competition or a cartel phase. A natural idea would be to compare the moments (say, mean or variance) of two distributions in order to tell them apart. However, as shown in Blanckenburg et al. (2012), none of the first four moments of the distribution, with an exception perhaps of variance, can be considered as a robust indicator allowing to distinguish between competition and cartel. In fact, a comparison of the whole distributions in each sub-period is needed.

Therefore, we suggest to employ the Kolmogorov-Smirnov test, which is a nonparametric (distribution-free) test comparing two distributions. In fact, the Kolmogorov- 
Smirnov D-statistic measures a distance between the empirical distribution functions of two samples. The null hypothesis of the test states that both samples are drawn from the same distribution. Formally, the test statistic is defined as follows:

$$
D=\sup _{\Delta P_{t}}\left|F_{0}\left(\Delta P_{t}\right)-F_{1}\left(\Delta P_{t}\right)\right|
$$

where $F_{0}\left(P_{t}\right)$ and $F_{1}\left(P_{t}\right)$ are the empirical cumulative distribution functions constructed for each of the two samples being compared; and $\Delta \mathrm{P}_{\mathrm{t}}$ is the variable of price changes in period $\mathrm{t}$. In words, the empirical cumulative distribution functions are compared (as absolute differences of function values) in each point of distribution support and then the largest absolute difference is taken as the Kolmogorov-Smirnov test statistic. When this supremum's absolute difference exceeds certain critical value, the null hypothesis of two samples being drawn from the same distribution is rejected.

The empirical density functions were obtained using the Gaussian kernel. The smoothing bandwidth for this kernel is computed using the following rule-of-thumb:

$$
B W=0.9 \frac{\min (\sigma, I Q R)}{1.34 T^{-1 / 5}}
$$

where $\sigma$ is the standard deviation; IQR is the interquartile range; and $T$ is the sample size. All computations are made using the programming language $\mathrm{R}$.

In fact, this question setting is equivalent to that of structural break, or regime switching detection. For instance, a period of free competition is succeeded by a cartel period, which represents a structural break or change in regime. Our task is to determine the timing of the structural break, which is typically unknown. As a matter of fact, six following situations are possible: 1) all the time competition; 2) all the time cartel; 3) first competition, then cartel; 4) first competition, then cartel, then again competition; 5) first cartel, then competition; and 6) first cartel, then competition, then again cartel. The most interesting case is 3), when we are actually trying to detect an existing cartel. The last situation is probably the least likely one, especially when the sample is short. Thus, we may have between 0 and 2 breakpoints. 
Similarly to the standard structural break tests with unknown break point (e.g., suplikelihood-ratio and sup-Wald tests described in Andrews, 1993) we need to run a sequence of KS-tests over rolling sub-periods (windows). However, in our case in addition to the breakpoint, $\tau$, we need to estimate also the length of window, w. Thus, the cartel phase, if any, is then defined given a combination of $\tau$ and $\mathrm{w}$, for which the maximum KS-statistic exceeding the critical value is attained. Formally:

$$
\left(\tau^{*}, w^{*}\right)=\underset{\tau, w}{\arg \max \left(D_{\tau, w}\right)}
$$

where $D_{\tau}$ is the KS test statistic, which compares the distributions of price changes in two sub-periods: 1) cartel-suspected sub-period $[T-w-\tau+2, T-\tau+1]$ and 2) the union of sub-periods before and after cartel-suspected sub-period $[2, T-w-\tau+1] \cup[T-\tau+2, T]$. Thus, if $\tau^{*}$ and $\mathrm{w}^{*}$ exist, then the cartel phase is defined as the time interval $\left[T-w^{*}-\tau^{*}+\right.$ $\left.2, T-\tau^{*}+1\right]$

The decision on accepting or rejecting the null hypothesis is made based on the pvalues corresponding to the Kolmogorov-Smirnov D-statistic. These are computed using bootstrap with the number of samples equal to 1000 .

A possible further development of the cartel testing technique can be supplementing the price information by the data on capacity utilization. In that case, a multivariate version of the Kolmogorov-Smirnov test could be used. This would allow comparing the joint distribution of prices and, for instance, capacity utilization and better identifying the cartels, since not only the behavior of the prices but also their relationship with quantity can change under cartel. 


\section{A short example and simulation results}

In this section, a short example of how manipulations can occur and how we are able to detect them will be introduced. In anticipation of the empirical section we choose a setup describing a common power market where supplier may be able to cause price inconstancies in order to gain market power. For this setup, we present four simulation scenarios and demonstrate how our empirical approach works.

Imagine a typical power market, where pricing underlie particular terms. It is not possible to store the generated power efficiently. As result, the storage of power is only possible for a marginal size. Consequently, power generation and the actual demand have to match. As a consequence, every hourly spot price is the pricing of a single product. The price of every hourly output is determined by the marginal costs of the last power plant that is needed to satisfy the demand. Figure 1 illustrates this principle. For more detail on this mechanism see, e. g., Sensfuß et al. (2008).

Figure 1: Merit-Order supply curve

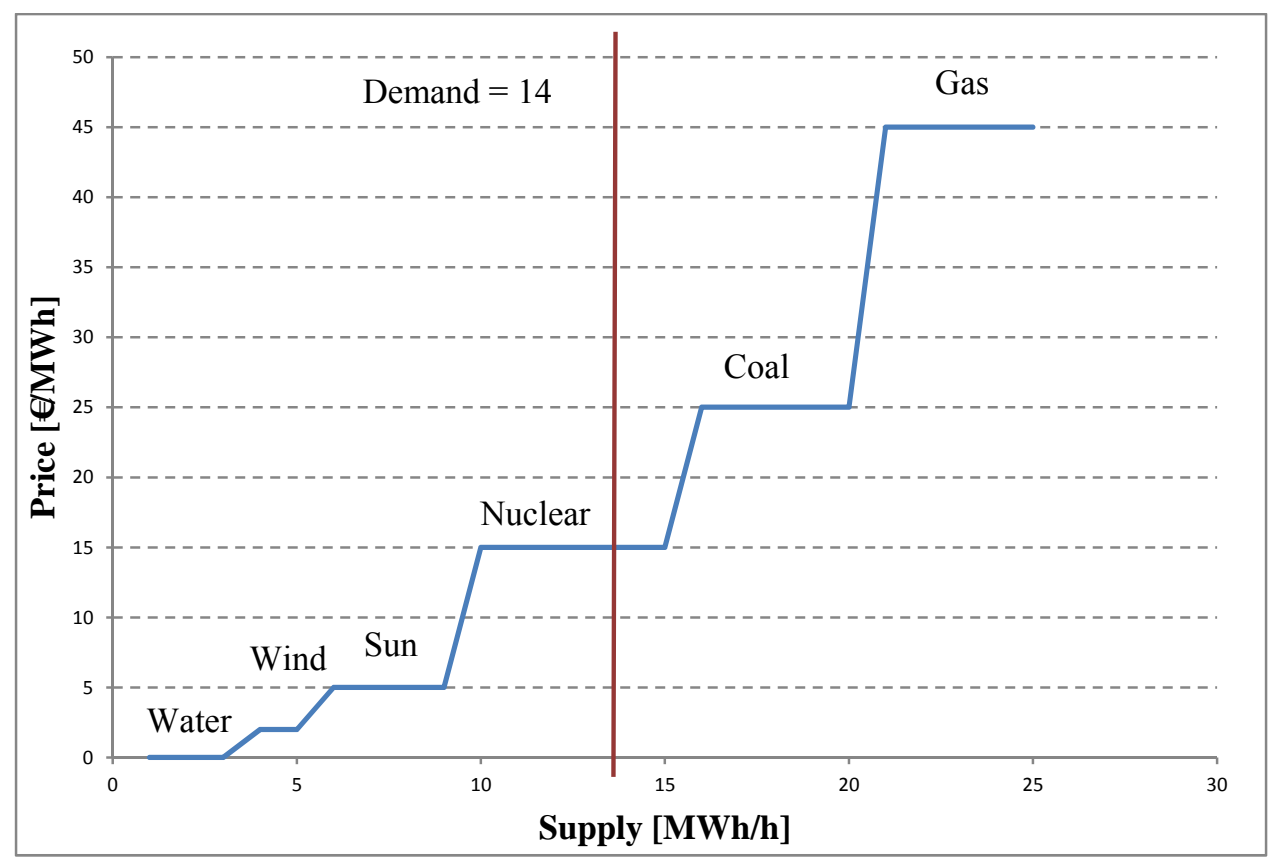


Assume that there exists a fictive pool of power plants. This pool consists of hydro power plants, wind power plants, photovoltaic power plants, nuclear power plants as well as of coal and gas power plants. The power plants are used to meet demand in order to cover their marginal costs. The plants with lower prices will be used before those with higher prices we speak about a merit-order supply function. In terms of Figure 1 it means the following: When demand is equal to $14 \mathrm{MWh} / \mathrm{h}$ (vertical line), the market price will be $15 € / \mathrm{MWh} / \mathrm{h}$. In order to meet the demand all hydro-, wind- and photovoltaic power plants must be put into operation. Moreover, additional $4 \mathrm{MWh} / \mathrm{h}$ must be generated by the nuclear power plants. Since the nuclear power plants are the last plants that will be needed to satisfy demand, the marginal costs of these plants determine the market price. As a result, all lower priced plants earn an additional profit margin above their marginal costs. Let us illustrate this using the example of the wind power plants. The marginal costs for the wind power plants are 2 $€ / \mathrm{MWh} / \mathrm{h}$; at a price of $15 € / \mathrm{MWh} / \mathrm{h}$ the wind power plants earn an additional margin of 13 $€ / \mathrm{MWh} / \mathrm{h}(15 € / \mathrm{MWh} / \mathrm{h}-2 € / \mathrm{MWh} / \mathrm{h})$. So the marginal plant earns only its marginal costs. Let us assume that the conventional nuclear, coal, and gas power plants are owned by a single company, so this company can exploit its market power by artificially restraining its capacities. For further literature regarding market power behavior in electricity markets see e.g. David and Wen (2001), Bunn and Oliveira (2003), Müsgens (2006), Weigt and Hirschhausen (2008). For example — as shown in Figure 2 - when the company reduces the power supply by $2 \mathrm{MWh} / \mathrm{h}$, then this would lead to a shift in the supply curve: The market price will now be determined by the coal power plants only and attain $25 € / \mathrm{MWh} / \mathrm{h}$. Consequently, all plants with marginal costs below $25 € / \mathrm{MWh} / \mathrm{h}$ will now earn an additional margin of $10 € / \mathrm{MWh} / \mathrm{h}$. 
Figure 2: Merit-Order supply curve with manipulation

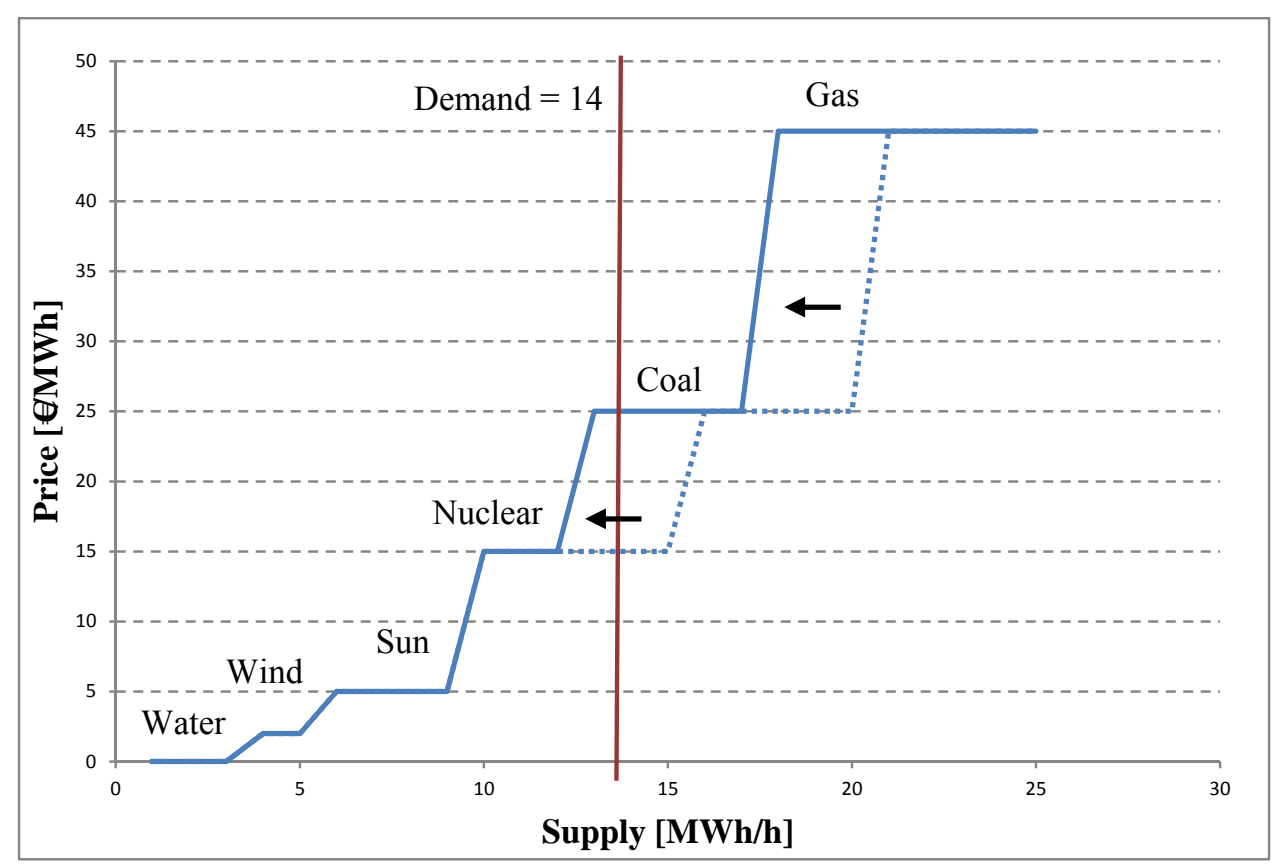

In this manner, the companies can exploit their market power as well as influence the market price and so they are able to obtain economic advantages. In order to demonstrate the usefulness of the screening technique explained in section III we use the following scenario. We stick to the aforementioned pool of power plants (see Figure 1) and approximate the supply function through a quadratic function. We concentrate on a time period of one year (365 days). For the sake of simplicity we take daily prices instead of hourly prices. The demand is modeled dynamically and underlies random variations. In every time period a market price is available. We will show the application of our approach with and without exploitation of market power for the following three cases.

a) Market power is not exploited: The supply function (the pool of power plants) is the same in every time period. 
b) Market power is exploited: In the time periods from 300 until 365 a systematic manipulation through restraining capacities takes place. Every restraint takes 10 days; after 10 days the restraint will increase to the next higher level.

c) Market power is exploited like in b) but the manipulation's intensity is incrementally reduced: The manipulation induced price changes will reduce in three steps $(80$ percent, 70 percent, 60 percent).

Figure 3 shows the absolute prices for case a) (see the upper panel) and the corresponding price changes (see the second panel from above). The third panel from above shows a case of the absolute prices with manipulation as well as the corresponding price changes for case b). 
Figure 3: Prices and price changes without (panels 1 and 2) and with (panels 3 and 4) manipulation
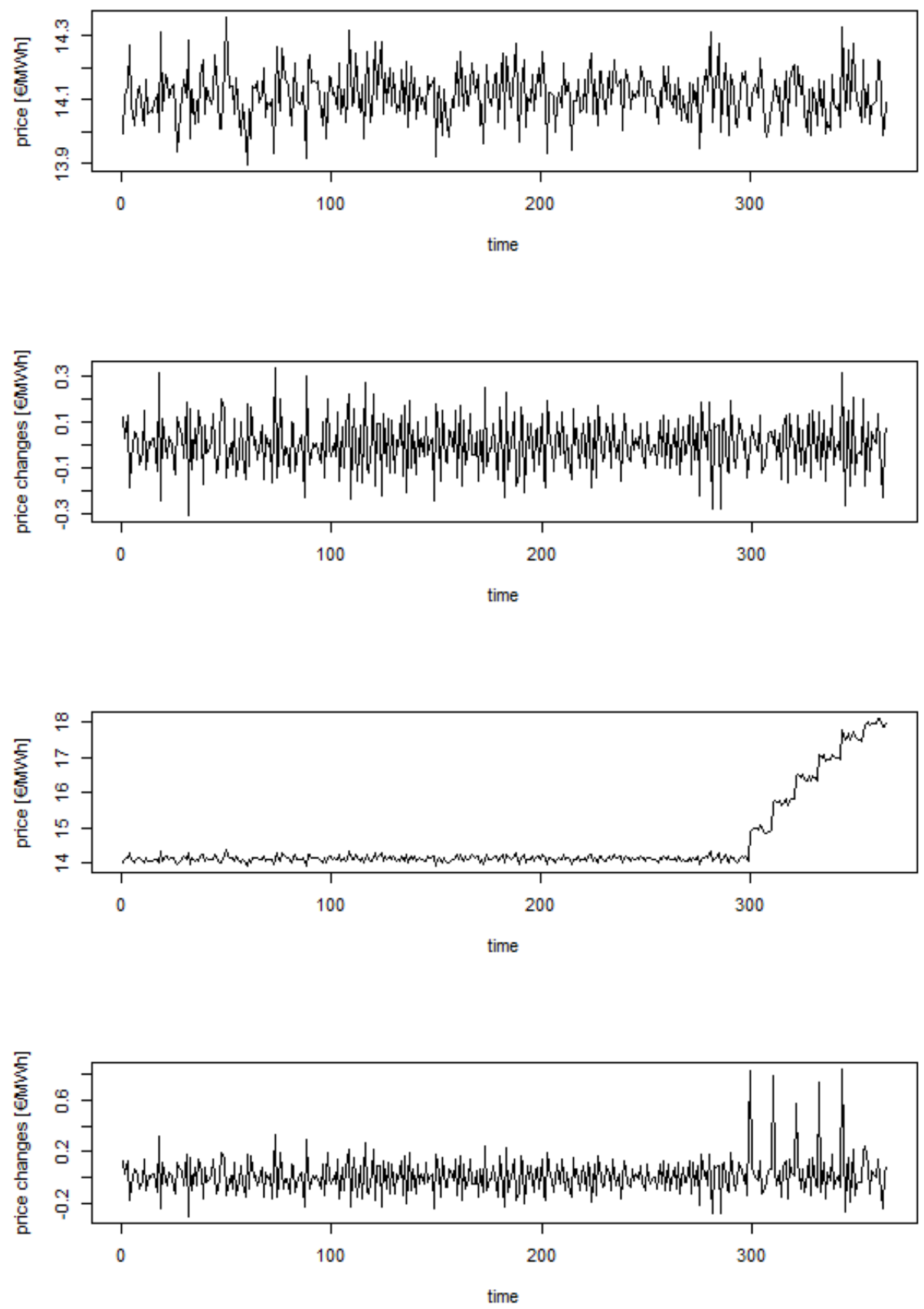
First of all we investigate the base scenario a). As expected, no abnormalities could be identified. For the sake of clarity of exposition, we do not present the results, however, they are available upon request. Instead, we investigate the case with 100 percent manipulation b) using the screening method. Since the manipulation period is unknown to the investigator, well an appropriate criterion for the choice of the window width is needed. We have run the screening with window widths from 1 day to 86 days. In order to identify the suspicious time period we look at the $p$-values. Table 1 reports all window widths, their starting and ending periods as well as the corresponding KS-statistic and the $p$-value. To save space we only show cases that are significant at a $99 \%$ level $(\mathrm{p}<0.01)$. As can be seen in Table 1 , all statistically significant windows are in the manipulation period.

Table 1: Results for $100 \%$ manipulation scenario

\begin{tabular}{|c|c|c|c|c|c|}
\hline No. & $\begin{array}{l}\text { Window } \\
\text { size }\end{array}$ & KS-statistic & p-value & Start & End \\
\hline 1 & 85 & 0.2038 & 0.007 & 274 & 358 \\
\hline 2 & 75 & 0.2251 & 0.005 & 284 & 358 \\
\hline 3 & 80 & 0.2103 & 0.003 & 284 & 363 \\
\hline 4 & 65 & 0.2364 & 0.006 & 294 & 358 \\
\hline 5 & 60 & 0.2446 & 0.007 & 295 & 354 \\
\hline 6 & 70 & 0.2302 & 0.004 & 295 & 364 \\
\hline 7 & 45 & 0.2583 & 0.008 & 305 & 349 \\
\hline 8 & 44 & 0.2445 & 0.009 & 307 & 350 \\
\hline 9 & 41 & 0.2536 & 0.008 & 308 & 348 \\
\hline 10 & 50 & 0.2618 & 0.007 & 309 & 358 \\
\hline 11 & 40 & 0.2669 & 0.009 & 309 & 348 \\
\hline 12 & 35 & 0.2811 & 0.008 & 309 & 343 \\
\hline 13 & 39 & 0.2673 & 0.008 & 309 & 347 \\
\hline 14 & 42 & 0.2728 & 0.005 & 309 & 350 \\
\hline 15 & 37 & 0.2796 & 0.003 & 309 & 345 \\
\hline 16 & 41 & 0.2722 & 0.003 & 309 & 349 \\
\hline 17 & 45 & 0.2805 & 0.001 & 310 & 354 \\
\hline 18 & 55 & 0.2435 & 0.008 & 310 & 364 \\
\hline 19 & 36 & 0.2696 & 0.009 & 310 & 345 \\
\hline 20 & 42 & 0.2583 & 0.009 & 310 & 351 \\
\hline 21 & 40 & 0.2762 & 0.008 & 310 & 349 \\
\hline 22 & 41 & 0.2687 & 0.006 & 310 & 350 \\
\hline 23 & 45 & 0.2805 & 0.003 & 310 & 354 \\
\hline 24 & 15 & 0.4098 & 0.009 & 331 & 345 \\
\hline 25 & 18 & 0.3754 & 0.009 & 331 & 348 \\
\hline 26 & 24 & 0.3256 & 0.009 & 331 & 354 \\
\hline 27 & 18 & 0.3725 & 0.007 & 332 & 349 \\
\hline
\end{tabular}


This is shown in Figure 4 (panel i). The vertical dashed line represents the starting time of the manipulation period. The manipulation period continues until the end of the investigation period. The blue rhombi symbolize the identified starting time points of the manipulation period for all statistically significant windows. The red quadratic points symbolize the identified ending time points of the manipulation period. Following up thereon, as described in case c), we have reduced the intensity of manipulation from 100 percent stepwise to 80 percent, 70 percent, and 60 percent.

It has been found that all windows identified in case b) are still statistically significant. Furthermore, as is shown in panel (ii) of Figure 4, nearly all identified manipulation periods belong to the true manipulation period. In the case of manipulation with a 70 percent intensity four windows (\# 1, 2, 3, and 4) are no longer significant — in comparison to the windows for the 100 percent case - and therefore are not shown. The windows of the \#27, 25, and 24 are statistically significant, but the identified cartel period does not correspond to the true manipulation period. All other windows correctly identify the manipulation period. In the case of a 60 percent manipulation intensity, only the windows \# 27, 25, and 24 are statistically significant. Panel (iv) of Figure 4 shows that no significant window coincides with the true manipulation period. 
Figure 4: Graphical characterization of manipulation scenarios i)-iv)

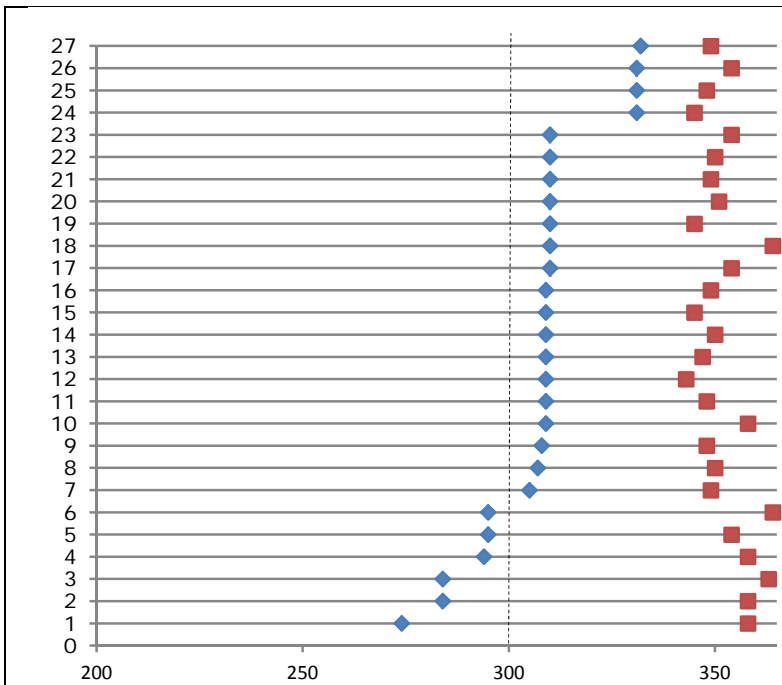

i) $100 \%$ manipulation

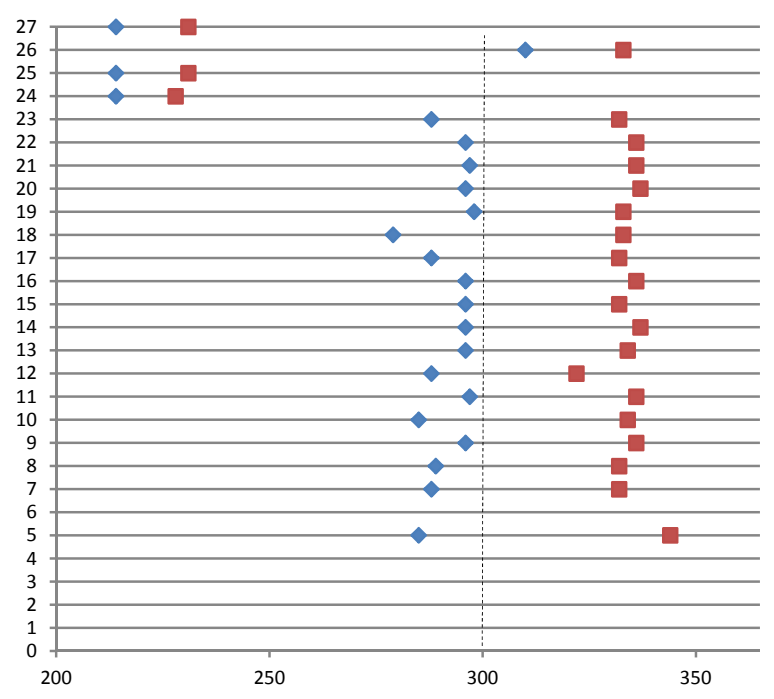

iii) $70 \%$ manipulation

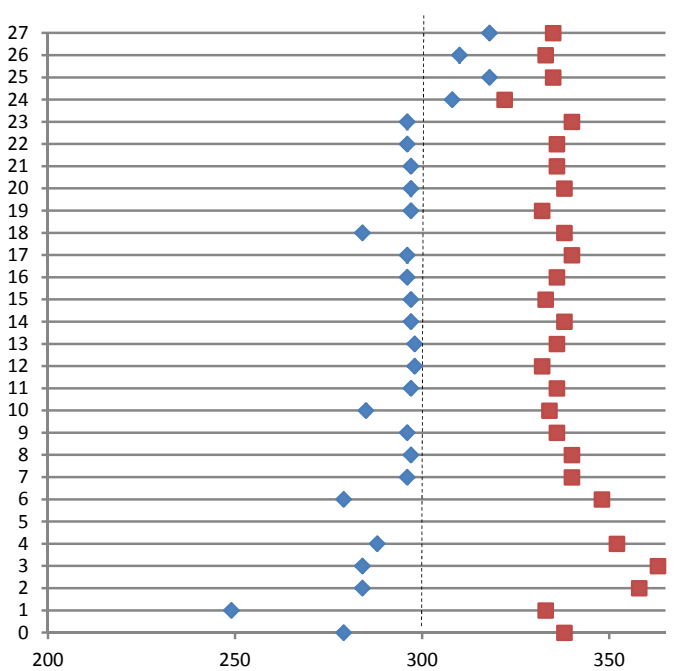

ii) $80 \%$ manipulation

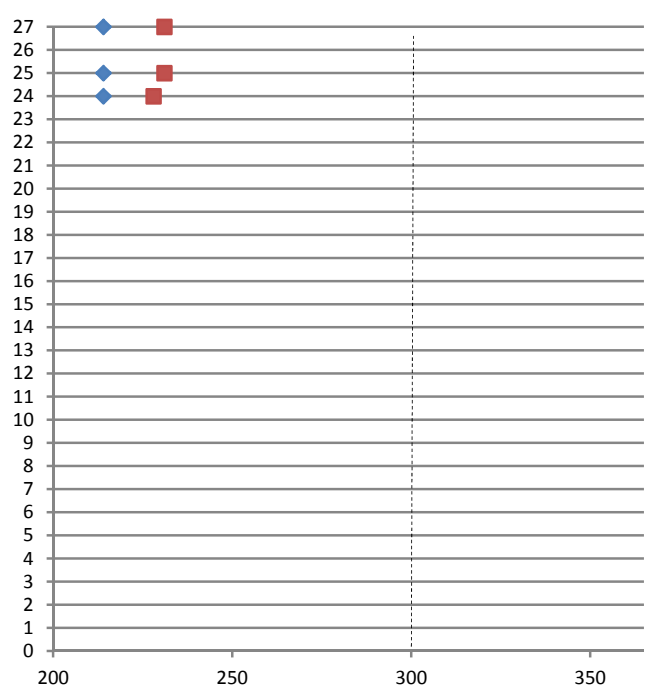

iv) $60 \%$ manipulation

The aim of this section was to illustrate the application of the screening method introduced in this paper. It can be shown that the test identifies manipulation periods sufficiently well. 


\section{Empirical application to German energy markets}

\section{a. Data description}

Here we use historical Phelix Base EPEX spot data as a measure for German power prices. Phelix refers to the Physical Electricity Index and is calculated and published as Phelix Base, a registered trademark of the European Energy Exchange AG (EEX). Average prices of the hours 1 to 24 for electricity traded on the spot market are used. Data are calculated for all calendar days of the year in the market area Germany disregarding power transmission bottlenecks. $^{2}$

Figure 5 shows prices and price changes on the German power market.

Figure 5: Prices and price changes on the German power market

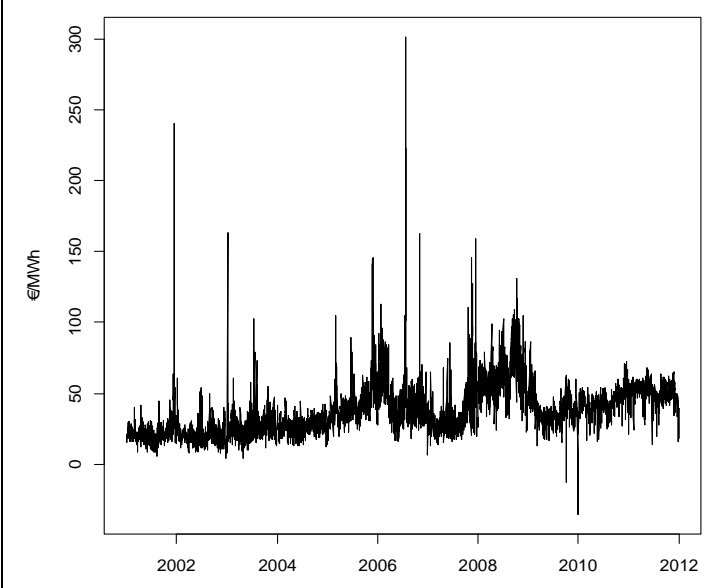

i) prices

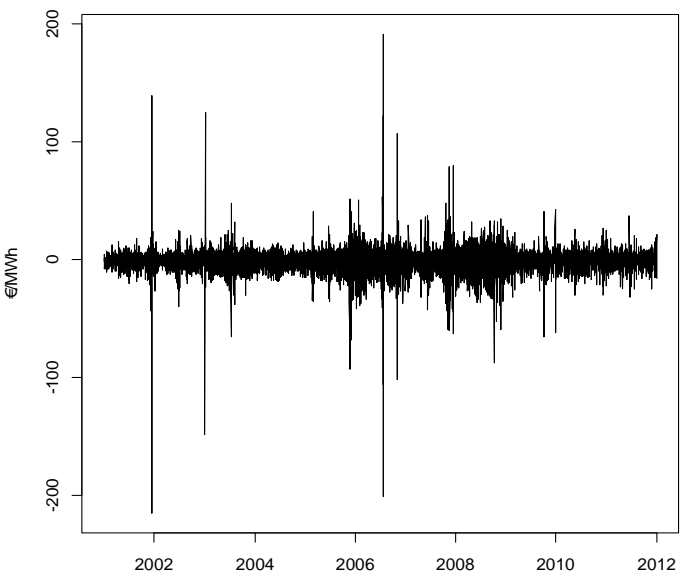

ii) price changes

In Table 2 descriptive statistics are presented. We use data with a timespan exceeding 10 years. Prices oscillate between $-35.57 € / \mathrm{MWh}$ and $301.5 € / \mathrm{MWh}$ with a mean of 40.12 $€ / M W h{ }^{3}$ However, only in very few cases the prices are negative. Most prices lie between the $1^{\text {st }}$ quantile of $26.91 € / \mathrm{MWh}$ and the $3^{\text {rd }}$ quantile of $49.72 € / \mathrm{MWh}$. Price changes oscillate

\footnotetext{
${ }^{2} \mathrm{http}$ ://static.epexspot.com/document/12848/EPEXSpot_Indices.pdf (retrieved 27 November 2012).

${ }^{3}$ Wholesale electricity markets sometimes result in prices below zero. In these cases, sellers pay buyers to take the power.
} 
around zero with a mean of $-0.01 € / \mathrm{MWh}$ and a median of $1.02 € / \mathrm{MWh}$. Most price changes lie between the $1^{\text {st }}$ quantile of $-4.18 € / \mathrm{MWh}$ and the $3^{\text {rd }}$ quantile of $5.77 € / \mathrm{MWh}$.

Table 2: Descriptive statistics of prices $(P)$ and price changes $(\Delta P)$.

\begin{tabular}{lll} 
& \multicolumn{1}{c}{$P$} & \multicolumn{1}{c}{$\Delta P$} \\
\hline Unit & $€ / \mathrm{MWh}$ & $€ / \mathrm{MWh}$ \\
Time span & $1 / 2 / 2001-8 / 2 / 2011$ & $1 / 3 / 2001-8 / 2 / 2011$ \\
Number of observations & 4,230 & 4,229 \\
Minimum & -35.57 & -214.8 \\
$1^{\text {st }}$ quantile & 26.91 & -4.18 \\
Median & 37.3 & 1.02 \\
Mean & 40.12 & -0.01 \\
$3^{\text {rd }}$ quantile & 49.72 & 5.77 \\
Maximum & 301.5 & 191.2 \\
\hline
\end{tabular}

\section{b. Results}

In order to detect whether price manipulations on German power markets occur, we used the earlier introduced methodology. Thereby, we need to run a sequence of KS-tests over rolling sub-periods. However, in our case, in addition to manipulation phases, we first need to estimate the length of window $w$. Assuming that we are only able to detect manipulated prices if they occur for a certain period, we set a minimum window to $w=30$ days $(\sim 1$ month $)$ and step of 1 day. In order to be able to detect possible long-term manipulations we increased $w$ from 30 to 750 days, to cover possible manipulations from 1 month up to 2 years.

Our results are presented in Table 3 . We identify five suspicious phases (I-V) where the distribution of price changes differs with large significance. Phase I starts in November and ends in December 2001. Phase II lies between October and November 2005, followed by Phase III with three suspicious windows between June and October 2006. After Phase IV (10/2007-11/2007) and Phase V (9/2008-10/2008) no more windows are detected until 02/2011. In all detected phases, KS-statistics are higher than 0.35 and significant at a $1 \%$ level. However, the windows that are significant at 5\%-10\% levels are not shown in Table 3 . It is worth noticing that no windows wider than 2 months were highly significant. That means we find no hint on long-term inconstancies. 
Table 3: Suspicious windows of price changes on the German power market 2001-2012

\begin{tabular}{|c|c|c|c|c|c|}
\hline \multirow[b]{2}{*}{ Phase } & \multicolumn{3}{|c|}{ Window } & \multirow[b]{2}{*}{ KS-statistic } & \multirow[b]{2}{*}{ p-value } \\
\hline & Start date & End date & Size & & \\
\hline \multirow{2}{*}{ I } & $11 / 18 / 2001$ & $12 / 18 / 2001$ & 30 & 0.4850 & 0.000 \\
\hline & $11 / 19 / 2001$ & $12 / 19 / 2001$ & 30 & 0.4121 & 0.000 \\
\hline \multirow{4}{*}{ II } & $10 / 30 / 2005$ & $11 / 29 / 2005$ & 30 & 0.3504 & 0.000 \\
\hline & $11 / 11 / 2005$ & $12 / 11 / 2005$ & 30 & 0.3621 & 0.001 \\
\hline & & & 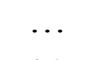 & & \\
\hline & $11 / 22 / 2005$ & $12 / 22 / 2005$ & 30 & 0.3659 & 0.000 \\
\hline \multirow{3}{*}{ III } & $6 / 28 / 2006$ & $7 / 28 / 2006$ & 30 & 0.4033 & 0.000 \\
\hline & $7 / 28 / 2006$ & $8 / 27 / 2006$ & 30 & 0.4321 & 0.000 \\
\hline & $10 / 9 / 2006$ & $11 / 8 / 2006$ & 30 & 0.3740 & 0.002 \\
\hline \multirow{3}{*}{ IV } & $10 / 19 / 2007$ & $11 / 18 / 2007$ & 60 & 0.3520 & 0.000 \\
\hline & & $\ldots$ & $\ldots$ & $\ldots$ & \\
\hline & $11 / 20 / 2007$ & $12 / 20 / 2007$ & 30 & 0.3778 & 0.001 \\
\hline \multirow{10}{*}{$\mathrm{V}$} & 9/7/2008 & $10 / 7 / 2008$ & 30 & 0.3628 & 0.002 \\
\hline & $9 / 8 / 2008$ & $10 / 8 / 2008$ & 30 & 0.3549 & 0.001 \\
\hline & $9 / 11 / 2008$ & $10 / 11 / 2008$ & 30 & 0.3581 & 0.001 \\
\hline & $9 / 12 / 2008$ & $10 / 12 / 2008$ & 30 & 0.3707 & 0.000 \\
\hline & $9 / 16 / 2008$ & $10 / 16 / 2008$ & 30 & 0.3564 & 0.000 \\
\hline & $9 / 18 / 2008$ & $10 / 18 / 2008$ & 30 & 0.3519 & 0.000 \\
\hline & $9 / 20 / 2008$ & $10 / 20 / 2008$ & 30 & 0.3550 & 0.000 \\
\hline & $9 / 21 / 2008$ & $10 / 21 / 2008$ & 30 & 0.3528 & 0.000 \\
\hline & $9 / 28 / 2008$ & $10 / 28 / 2008$ & 30 & 0.3721 & 0.001 \\
\hline & $9 / 29 / 2008$ & $10 / 29 / 2008$ & 30 & 0.3857 & 0.000 \\
\hline
\end{tabular}

Note: Only KS-statistics, which are significant at a $99 \%$ level, are shown.

Dots (...) represent a continuum in days (e.g. 11/11/2005 until 11/22/2005).

All Windows have significant KS-Statistics in these days.

Figure 6 illustrates our results. One can easily identify the five detected phases. To highlight these suspected periods we inserted a horizontal line at KS-statistic value of 0.35 . 
Figure 6: Inconsistencies in price changes on the German power market 2001-2012

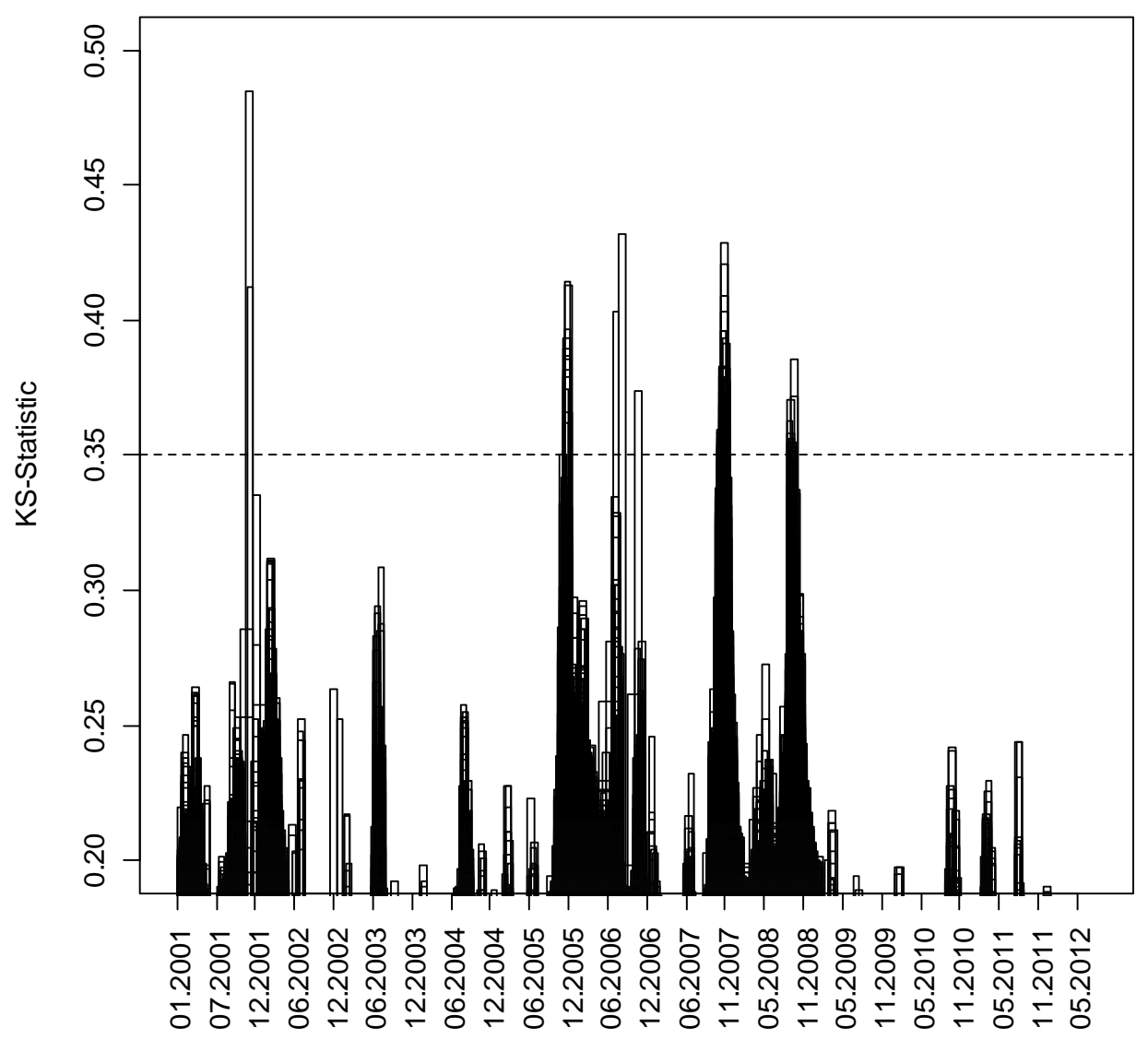

\section{Conclusion}

Our paper develops a market screening model to detect inconstancies in price changes. Following requirements for systematic and ubiquitous market screenings of Harrington $(2005,2008)$, we present a robust model to detect inconstancies systematically. Our nonparametric rolling window approach can be used, e.g., for generating the initial suspicion of a collusive period. In this paper, we illustrate our approach with a short market simulation in a common energy market setup including merit-order effects. We find, that the power of the results highly depend on the strength and length of the manipulation period itself. We show in simulation results, that the KS-test delivers robust results and that $p$-values are consistent with the strength and the relation of manipulation period to overall data. To make it clear, if the manipulation period is very short, $p$-values will be too large and hence test statistics will be 
insignificant. However, manipulations can be detected if they hold up at least one month, using daily data.

Finally, we adopt the model to German electricity markets. According to our results, between 2001 and 2011 energy suppliers were probably successful in controlling the market price for several phases. We detect five suspicious phases in which the observed distribution of price changes differ with highly significance. Phase I (11/2001-12/2001), Phase II (10/2005-11/2005), Phase III (06/2006-10/2006), Phase IV (10/2007-11/2007), and Phase V (9/2008-10/2008). We do not provide economic explanations of the detected suspicious phases in this paper. However, Müsgens (2006) uses data for the German power market from 06/2000-06/2003 and finds for a few months after August 2001 strong evidence for market power. This is consonant with our results. Other empirical possibilities for comparisons do not exist so far.

Further research would be to apply the proposed model to other markets. Thereby an application to other data is possible as well. For instance, antitrust agencies (or other institutions) may access capacity utilization or financial data. Moreover, taking into account macroeconomic events, such as a phase of the business cycle, could be useful. However, this paper shows how our model could easily be used in a general screening. In addition, there is a necessity for further developments concerning the proposed methods for model validation. 


\section{References}

Andrews, D. W. K. (1993). Tests for Parameter Instability and Structural Change with Unknown Change Point, Econometrica, 61(4), 821-856.

Abrantes-Metz, R. M., Froeb, L. M., Geweke, J., Taylor, C. T. (2006). A Variance Screen for Collusion. International Journal of Industrial Organization, 24, 467-486.

Blanckenburg, K.v., Geist, A. and Kholodilin, K.A. (2012). The Influence of Collusion on Price Changes: New Evidence from Major Cartel Cases, German Economic Review, 13(3), 245-256.

Blanckenburg, K.v. and Geist, A. (2011): Detecting Illegal Activities: The Case of Cartels, European Journal of Law and Economics, 32(1), 15-33.

Blanckenburg, K.v. and Geist, A. (2009): How Can a Cartel be Detected?, International Advances in Economic Research, 15(4), 421-436.

Boeckers, V., Haucap, J. and Heimeshoff, U. (2011): Screening for Collective Dominance: The Case of the European Mobile Telecommunications, http://ssrn.com/abstract=1909545.

Bolotova, Y., Connor, J. M. and Miller D. J. (2008): The Impact of Collusion on Price Behavior: Empirical Results from Two Recent Cases, International Journal of Industrial Organization, 26, 1290-1307.

Brunn, D.W., Oliveira, F.S. (2003): Evaluating Individual Market Power in Electricity Markets via Agent-Based Simulation, Annals of Operations Research, 121(1-4), 57-77.

Carlson, J. and McAfee, R. (1983): Discrete Equilibrium Price Dispersion, Journal of Political Economy, 91 (3), 480-493.

Carlton, D.W. (1986): The rigidity of prices, American Economic Review, 76, 637-658.

Connor, J. M. (2005): Collusion and Price Dispersion, Applied Economics Letters, 12, 335338. 
Harrington, J. (2008): Detecting Cartels, Handbook in Antitrust Economics, Buccirossi, P. (ed.), MIT Press, Chapter 6, 213-258.

Harrington, J. (2005): Optimal Cartel Pricing in the Presence of an Antitrust Authority. International Economic Review, 46(1), 145-169.

Heijnen, P., Haan, M.A., Soetevent, A.R. (2012): Screening for Collusion: A Spatial Statistics Approach, Tinbergen Institute Discussion Papers, No. 12-058.

Hüschelrath, K., Veith, T. (2011): Cartel detection in procurement markets, ZEW Discussion Papers, No. 11-066.

Kumar David, A., Wen, F. (2001): Market power in electricity supply, IEEE Trans Energy Conversion, 4(3), 61-92.

Müsgens, F. (2006): Quantifying Market Power in the German Wholesale Electricity Market using a Dynamic Multi-Regional Dispatch Model, The Journal of Industrial Economics, $\operatorname{LIV}(4), 471-498$.

Sensfuß, F., Ragwitz, M., Genoese, M. (2008): The merit-order effect: A detailed analysis of the price effect of renewable electricity generation on spot market prices in Germany, Energy Policy, 36(8), 3086-3094.

Sherwin, Robert A., and George J. Stigler (1985): The Extent Of The Market, Journal of Law and Economics, 28, 555-586.

Stigler, G. (1964): A theory of oligopoly, Journal of Political Economy, 72(1), 44-61.

Weigt, H., Hirschhausen, C. (2008): Price formation and market power in the German wholesale electricity market in 2006, Energy Policy, 36(11), 4227-4234. 